\title{
Conf-9509287--1
}

$$
\begin{aligned}
& \text { TIATIVED } \\
& \text { 1ำ } 3 \text { i } 1995 \\
& \text { ज } 11
\end{aligned}
$$

\section{EVALUATION OF METAL AND RADIONUCLIDE DATA FROM NEUTRON ACTIVATION AND ACID-DIGESTION-BASED SPECTROMETRY ANALYSES OF BACKGROUND SOLS: SIGNIFICANCE IN ENVIRONMENTAL RESTORATION}

S. Y. LEE*, D. R. WATKINS*, B. L. JACKSON*, R. L. SCHMOYER*, D. A. LIETZKE**, B. B. BURGOA**, J. T. BRANSON**, J. T. AMMONS**

* Oak Ridge National Laboratory, Oak Ridge, Tennessee, 37831 USA

** The University of Tennessee, Knoxville, Tennessee, 37916 USA

For Journal of Radioanalytical and Nuclear Chemistry

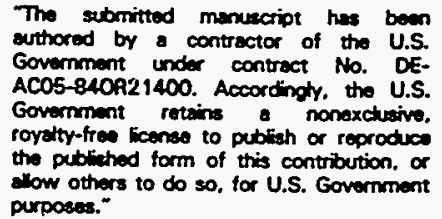

purposes." 


\title{
EVALUATION OF METAL AND RADIONUCLIDE DATA FROM NEUTRON ACTIVATION AND ACID-DIGESTION-BASED SPECTROMETRY ANALYSES OF BACKGROUND SOILS: SIGNIFICANCE IN ENVIRONMENTAL RESTORATION
}

\author{
S. Y. LEE*, D. R. WATKINS*, B. L. JACKSON*, R. L. SCHMOYER*, \\ D. A. LIETZKE**, B. B. BURGOA**, J. T. BRANSON**, J. T. AMMONS** \\ * Oak Ridge National Laboratory, Oak Ridge, Tennessee, 37831 USA \\ ** The University of Tennessee, Knoxville, Tennessee, 37916 USA
}

\begin{abstract}
A faster, more cost-effective, and higher-quality data acquisition procedure for natural background-level metals and radionuclides in soils is needed for remedial investigations of contaminated sites. In this project, a total of 120 soil samples were collected from uncontaminated areas on and near the Oak Ridge Reservation. The samples were taken at three different depths and from three different geologic groups to establish background concentrations of metals and radionuclides. The objective of this presentation is to discuss the advantages and disadvantages of neutron activation analysis (NAA) compared with those of acid-digestionbased spectrometry (ADS) methods; the advantages and disadvantages were evaluated from $\mathrm{Al}, \mathrm{Sb}, \mathrm{As}, \mathrm{Cr}, \mathrm{Co}$, $\mathrm{Fe}, \mathrm{Mg}, \mathrm{Mn}, \mathrm{Hg}, \mathrm{K}, \mathrm{Ag},{ }^{232} \mathrm{Th},{ }^{235} \mathrm{U},{ }^{238} \mathrm{U}, \mathrm{V}$, and $\mathrm{Zn}$ data. The ADS methods used for this project were inductively coupled plasma (ICP), ICP-mass spectrometry (ICP-MS), and alpha spectrometry. The scatter plots showed that the NAA results for As, $\mathrm{Co}, \mathrm{Fe}, \mathrm{Mn},{ }^{232} \mathrm{Th}$, and ${ }^{238} \mathrm{U}$ are reasonably correlated with the results from the other analytical methods. Compared to NAA, however, the ADS methods underestimated $\mathrm{Al}, \mathrm{Cr}, \mathrm{Mg}, \mathrm{K}$, $\mathrm{V}$, and $\mathrm{Zn}$. The skew distributions were caused by incomplete dissolution of the analytes during acid digestion of the soil samples. Because of the high detection limits of the spectrometric methods, the NAA results and the $\mathrm{ADS}$ results for some elements, including $\mathrm{Sb}, \mathrm{Hg}$, and $\mathrm{Ag}$, did not show a definite relationship. The NAA results were highly correlated with the alpha spectrometry results for ${ }^{232} \mathrm{Th}$ and ${ }^{238} \mathrm{U}$ but poorly correlated for ${ }^{235} \mathrm{U}$, probably because of a larger counting error associated with the lower activity of the isotope. The NAA methods, including the delayed neutron counting method, were far superior techniques for quantifying background levels of radionuclides $\left({ }^{232} \mathrm{Th},{ }^{235} \mathrm{U}\right.$, and ${ }^{238} \mathrm{U}$ ) and metals $(\mathrm{Al}, \mathrm{Cr}, \mathrm{Mg}, \mathrm{K}, \mathrm{V}$, and $\mathrm{Zn}$ ) in soils.
\end{abstract}

Remediation of environmental contamination is necessary to prevent further degradation of our environment and to lower risk to human health. The past 50 years of uranium enrichment processes, nuclear weapon production, and energy research and development activities have resulted in serious environmental problems on the Oak Ridge Reservation (ORR) in Oak Ridge, Tennessee, USA. The contaminated sites are located on different soil series developed from different parent materials (geologic formations) throughout ORR. Background concentrations of potential contaminants in the soils need to be established to delineate contaminated areas, as well as to determine cleanup levels of the remediating sites. Therefore, a comprehensive Background Soil Characterization Project (BSCP) was developed for site-specific remedial investigation and feasibility studies at $O R R^{1}$. Site characterization is usually expensive, and analytical cost is one of the major contributors to the site characterization cost, which itself is only a portion of the overall environmental remediation costs. Analytical costs for background soils will be even higher than those for contaminated soils because establishment of the background level requires a lower detection limit and a higher level of quality control and data evaluation. 
Detection limits for target analytes depend on the instrumental detection limit and on the sample preparation method. An acid-digestion-based spectrometry (ADS) method that has been standardized by the U.S. Environmental Protection Agency (EPA) is commonly used as a pretreatment (extraction or digestion) for various spectrometric analyses of metals and radionuclides in soils ${ }^{2}$. This method, however, cannot avoid dilution of the target elements and the uncertainty associated with the completeness of the dissolution. Such pitfalls of the ADS method might represent a minor problem for highly contaminated soil analyses but could be a significant data quality problem for the determination of background soil concentrations. Because of its nonintrusive nature, the neutron activation analysis and delayed neutron counting (NAA) method might circumvent such problems for most target elements, although NAA is not currently a standard method for EPA procedures and is not applicable for some metals in soils.

The objective of this investigation was to evaluate the NAA method against the EPA-approved ADS methods by using simple statistical analyses of the data iil the database ${ }^{3}$ generated during BSCP. Environmental restoration projects require an economical and reliable method of getting data for soil analyses. The ORR database contains data on background concentrations of potential contaminants as well as data on major soil components and has been used by many site environmental remediation projects at $\mathrm{ORR}^{4}$.

\section{Experimental}

Materials: A total of 120 soil sampling sites inside and outside ORR were selected. Soils in the study area are developed from three principal geologic groups: the Conasauga (shale), the Knox (dolomite), and the Chickamauga (limestone) groups. Three soil samples each representing a different soil horizon were collected from each type of soil formation. In addition, three randomly selected soil samples from the same horizon, geologic group, and general location were composited. Therefore, the total number of samples was 120 for each analyte. The actual number of samples in the analytical data set, however, was $\leq 120$ for each analyte because some of the results were rejected during data validation.

Analytical Methods: A procedure for comparative instrumental NAA of about 40 chemical elements in soils was developed at the NAA facility at Oak Ridge National Laboratory (ORNL) ${ }^{5,6}$. Two specimens were prepared from each soil sample; the first specimen was for elements that yield radionuclides with half-lives of a few hours or less, and the second specimen was for elements that yield radionuclides with half-lives of about one-half day or longer. The second specimen was reirradiated in a pneumatic tube and counted for delayed neutron activity to determine the quantity of ${ }^{235} \mathrm{U}$. In the comparative NAA method, the quantity of an element in the unknown sample was computed from the disintegration rates determined for samples of unknown concentration and from the disintegration rates determined from standards for samples containing known amounts of the desired element.

For determination of nonradioactive metals (designated as simply metals), soil samples were digested in nitric acid at $95^{\circ} \mathrm{C}$ and oxidized with hydrogen peroxide. After filtration or centrifugation, the sample solutions were diluted and then analyzed by either inductively coupled plasma spectrometry (ICP) or ICP-mass spectrometry (ICP-MS) ${ }^{7}$. Fe, $\mathrm{Mg}, \mathrm{K}, \mathrm{Na}$, and V were analyzed by ICP, whereas $\mathrm{Al}, \mathrm{Sb}, \mathrm{As}, \mathrm{Ba}, \mathrm{Cr}, \mathrm{Co}, \mathrm{Mn}$, and $\mathrm{Zn}$ were analyzed by ICP-MS. For $\mathrm{Hg}$ analysis, the cold-vapor atomic absorption (CVA) technique ${ }^{8}$ was used after extraction of the soils with sulfuric acid, nitric acid, and potassium permanganate solutions. Naturally occurring Th and $\mathrm{U}$ isotope series in the soil were analyzed by alpha spectrometry after nitric acid digestion, solvent 
extraction, and plating?. Because comparison of the NAA method with ADS methods is the main interest of this paper, all non-NAA methods are referred to as the ADS method.

Statistical analyses: The number of soil samples analyzed was 120 , but the actual number of data sets for individual analytes ranged from 97 to 120 . The differences in the number of data sets were from the rejection of unusable data during data validation and assessment. Most of the data were values above the detection limit ("detects"), but $100 \%$ of the Sb and Ag data from ICP-MS and $44 \%$ of the $\mathrm{Hg}$ data from CVA were values below the detection limit ("undetects"). NAA and ADS results were compared in terms of (1) arithmetic mean and standard deviation (one sigma) using paired $t$-test ${ }^{10}$ and (2) slope from zero-intercept simple linear regressions of ADS results on NAA results using $t$-test of the hypothesis that the slope is $1.0^{11}$.

\section{Results and Discussion}

The primary purpose of analyzing background soil samples using NAA was to investigate the relationship between the NAA method and the corresponding ADS method. The NAA method is not a standard EPA contract-laboratory method (Resource Conservation Recovery Act method) for metals. The NAA method has rarely been used for site characterization projects related to EPA Superfund and U.S. Department of Energy Environmental Restoration programs, although it has been used for soil and rock analysis ${ }^{12}$. The major difference between the two methods is in preparation of the soil samples before analysis. The NAA method does not require acid extraction or dissolution steps, which are major sources of potential error for the ADS method. Some elements may be readily extracted, but others, such as refractory elements, may not be completely dissolved during acid digestion. Soils on ORR are composed mainly of organic material and minerals such as quartz, illite, kaolinite, micas, feldspars, and iron oxides ${ }^{13}$. The inorganic elements that are of concern for environmental remediation are present in a form adsorbed onto organic and mineral surfaces, or as a part of the mineral structure. The hypothesis of this study is that the ADS method will underestimate the analyte concentrations, particularly the concentrations of metals associated with refractory elements in the silicate minerals, provided other data quality parameters remain equal. In a test of this hypothesis, 16 elements and two uranium isotopes were analyzed using both methods (Table 1).

For each analyte, the NAA results were compared to the ADS results through estimated arithmetic mean values and significance of their difference (Table 1). The means of the NAA results were greater than the means of the ADS results for most analytes, except As, Mn, and both $\mathrm{U}$ isotopes. The pair of means, however, were not noticeably different from each other if the standard deviations of the pair were considered. For example, the mean values of aluminum were significantly different, but the lower values of the NAA data overlapped with the upper values of the ADS data. The standard deviation of each analyte was relatively large, but this is believed to be the result of sample variability rather than analytical error. The sampling plan for BSCP was prepared to statistically determine the variability contributed by the differences in sampling depth (soil horizon), soil formation (mineral weathering), parent rock type (geologic group), and sampling location (geography). The correlation statistics of the variables were presented in the BSCP report ${ }^{1}$. Because of the embedded variability by sampling design, the difference between the NAA results and the ADS results was tested by a paired $t$-test method rather than by a method using the difference of means of the analytes (Table 1). 
Table 1

Analytical results for metals and radionuclides, determined by the NAA and ADS methods, and reference data from the eastern United States, $\mathrm{mg} / \mathrm{kg}$

\begin{tabular}{|c|c|c|c|c|c|c|c|}
\hline \multirow{2}{*}{ Element } & \multicolumn{2}{|c|}{ NAA } & \multicolumn{2}{|c|}{$\mathrm{ADS}$} & \multirow{2}{*}{$\begin{array}{l}\text { Paired } \\
t \text {-test }\end{array}$} & \multicolumn{2}{|c|}{ Eastern U.S." } \\
\hline & Mean & Std dev & Mean & Std dev & & Mean & Range \\
\hline $\mathrm{Al}$ & 66,000 & 31,000 & 23,500 & 10,100 & 0.0001 & 57,000 & $7,000-100,000$ \\
\hline $\mathrm{Sb}$ & 0.70 & 0.43 & 0.5 & 0.32 & 0.0001 & 0.76 & $<1-8.8$ \\
\hline As & 14.7 & 16.6 & 15.5 & 21.6 & 0.5290 & 7.4 & $0.1-73$ \\
\hline $\mathrm{Cr}$ & 64.3 & 21.7 & 30.7 & 11.3 & 0.0001 & 52 & $1-1,000$ \\
\hline Co & 14.0 & 9.2 & 12.8 & 9.4 & 0.0240 & 9.2 & $<0.3-70$ \\
\hline $\mathrm{Fe}$ & 36,600 & 14,100 & 34,600 & 12,400 & 0.0021 & 25,000 & $100-100,000$ \\
\hline $\mathrm{Mg}$ & 5,240 & 2,860 & 1,860 & 1,330 & 0.0001 & 4,600 & $50-50,000$ \\
\hline $\mathrm{Mn}$ & 570 & 569 & 684 & 659 & 0.0034 & 640 & $<2-7000$ \\
\hline $\mathrm{Hg}$ & 0.97 & 0.33 & 0.16 & 0.10 & 0.0001 & 0.12 & $0.01-3.4$ \\
\hline $\mathrm{K}$ & 15,300 & 10,100 & 2,110 & 1,500 & 0.0001 & 12,000 & $50-37,000$ \\
\hline $\mathrm{Ag}$ & 1.80 & 0.66 & 1.21 & 0.46 & 0.0001 & $0.05^{\mathrm{b}}$ & $0.01-5^{b}$ \\
\hline${ }^{232} \mathrm{Th}$ & 11.26 & 3.29 & 10.66 & 4.17 & 0.1057 & $8.6^{\circ}$ & $2.2-23^{\mathrm{e}}$ \\
\hline${ }^{235} \mathrm{U}$ & 0.023 & 0.008 & 0.058 & 0.056 & 0.0001 & $0.019^{d}$ & $0.002-0.079^{d}$ \\
\hline${ }^{238} \mathrm{U}$ & 3.87 & 1.11 & 4.03 & 1.75 & 0.3358 & $2.7^{\mathrm{c}}$ & $0.29-11^{c}$ \\
\hline V & 81.0 & 32.0 & 45.4 & 16.3 & 0.0001 & 66 & $<7-300$ \\
\hline $\mathrm{Zn}$ & 122.9 & 91.9 & 67.3 & 53.1 & 0.0001 & 52 & $<5-2900$ \\
\hline
\end{tabular}

${ }^{2}$ From H. T. Shacklette, J. G. Boerngen, Elemental Concentrations in Soils and Other Surficial materials of the Conterminous United States, U.S. Geological Survey Professional Paper 1270, U.S. Government Printing Office, Washington, D.C., USA (1984).

${ }^{b}$ From W. L. Lindsay, Chemical Equilibria in Soils, John Wiley \& Sons, New York, N.Y., USA (1979).

${ }^{\circ}$ Concentration of total Th or U.

${ }^{\mathrm{d}}$ Calculated value from total $U$.

The paired $t$-test of the analytes showed that the $\mathrm{ADS}$ results for $\mathrm{Al}, \mathrm{Sb}, \mathrm{Cr}, \mathrm{Mg}, \mathrm{Hg}, \mathrm{K}, \mathrm{Ag}$, ${ }^{235} \mathrm{U}, \mathrm{V}$, and $\mathrm{Zn}$ were significantly different $(0.0001)$ from the NAA results (Table 1$)$. Because most of the ADS values were undetects, significant differences between the two methods for $\mathrm{Sb}$, $\mathrm{Hg}$, and $\mathrm{Ag}$ were expected. The undetects from the $\mathrm{ADS}$ method were used for only data evaluation and interpretation and should be treated differently from detects, which were used for calculating means for the analytes. The $t$-test results also suggested that the ADS means for As, $\mathrm{Mn},{ }^{235} \mathrm{U}$, and ${ }^{238} \mathrm{U}$ were greater than the NAA means but not significantly different, except in the case of ${ }^{235} \mathrm{U}$. The significantly greater values for ${ }^{235} \mathrm{U}$ resulted from analytical quality problems at the analytical laboratory rather than from the ADS method itself. The greater values could be attributed to a high detection limit for the undetects and a high background counting for the ${ }^{235} \mathrm{U}$ energy region.

On the basis of paired $t$-test results, the 16 analytes were classified into four groups: a group of analytes underestimated by the ADS method (Group A), a group with no significant differences between the two methods (Group B), a group with detection problems associated with the ADS method (Group C), and a group of radionuclides (Group D). In verifying the grouping based on the relationship between the NAA method and the ADS method, the corresponding results were examined through graphics, regression, and significance of the deviation from the ideal slope of 1.0. The scatter diagrams for the corresponding data set are presented in Figs 1, 2, and 3. The regression slopes and the results of the significance test of hypothesis are summarized in Table 2. 

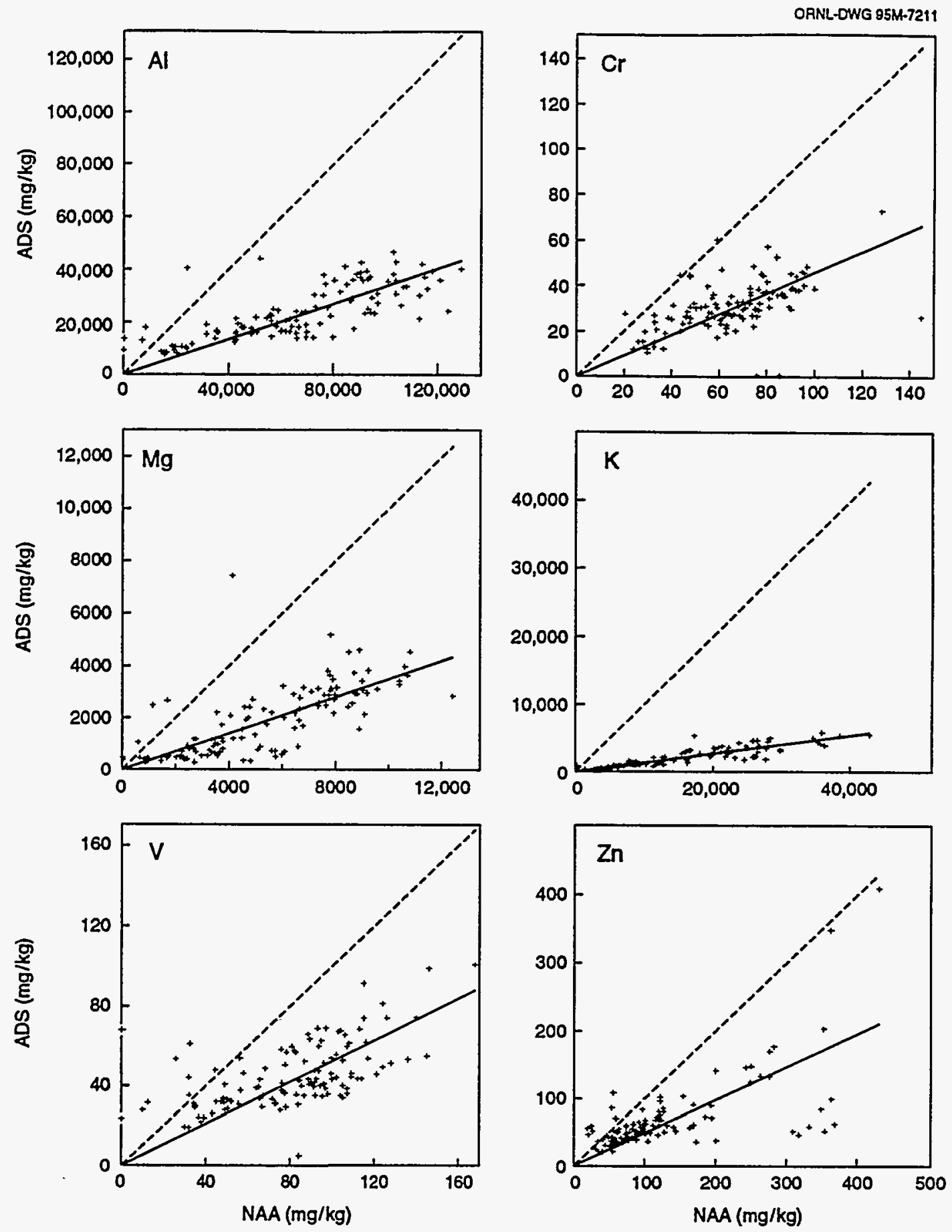

Fig.1. Scatter diagrams of $\mathrm{Al}, \mathrm{Cr}, \mathrm{Mg}, \mathrm{K}, \mathrm{V}$, and $\mathrm{Zn}$ concentrations determined by the ADS and NAA methods. 
Table 2

Summary of correlation and regression statistics of NAA and ADS results

\begin{tabular}{ccccc}
\hline Group & Element & Number & Regression slope & Significance \\
\hline $\mathrm{A}$ & $\mathrm{Al}$ & 118 & 0.34 & 0.0001 \\
$\mathrm{~A}$ & $\mathrm{Cr}$ & 118 & 0.46 & 0.0001 \\
$\mathrm{~A}$ & $\mathrm{Mg}$ & 118 & 0.35 & 0.0001 \\
$\mathrm{~A}$ & $\mathrm{~K}$ & 117 & 0.14 & 0.0001 \\
$\mathrm{~A}$ & $\mathrm{~V}$ & 118 & 0.52 & 0.0001 \\
$\mathrm{~A}$ & $\mathrm{Zn}$ & 115 & 0.49 & 0.0001 \\
$\mathrm{~B}$ & $\mathrm{As}$ & 115 & 1.01 & 0.8905 \\
$\mathrm{~B}$ & $\mathrm{Co}$ & 118 & 0.89 & 0.0004 \\
$\mathrm{~B}$ & $\mathrm{Fe}$ & 118 & 0.92 & 0.0001 \\
$\mathrm{~B}$ & $\mathrm{Mn}$ & 120 & 1.05 & 0.2881 \\
$\mathrm{C}$ & $\mathrm{Sb}$ & 116 & 0.51 & 0.0001 \\
$\mathrm{C}$ & $\mathrm{Hg}$ & 117 & 0.14 & 0.0001 \\
$\mathrm{C}$ & $\mathrm{Ag}$ & 117 & 0.59 & 0.0001 \\
$\mathrm{D}$ & ${ }^{232} \mathrm{Th}$ & 118 & 0.92 & 0.0087 \\
$\mathrm{D}$ & ${ }^{235} \mathrm{U}$ & 97 & 2.10 & 0.0001 \\
$\mathrm{D}$ & ${ }^{238} \mathrm{U}$ & 115 & 0.99 & 0.9954 \\
\hline
\end{tabular}

Each of the Group $\mathrm{A}$ analytes $(\mathrm{Al}, \mathrm{Cr}, \mathrm{Mg}, \mathrm{K}, \mathrm{V}$, and $\mathrm{Zn}$ ) had a very low paired $t$-test value $(0.0001)$, showing a significant difference between the NAA results and the ADS results, and had a regression slope of $\leq 0.52$, suggesting significant deviation from the ideal slope toward the $x$ axis. Scatter diagrams of this group are presented in Fig. 1. The distribution and statistical analyses suggested that the ADS method underestimated the Group A analytes. The results further suggested that silicate minerals in the soils were either incompletely or incongruently dissolved during the acid digestion. Most of the Group A analytes, except chromium and zinc, are common components of the layered silicate minerals, such as illite and mica in the soils. Chromium and zinc should behave like the metals of Group B. The unexpected behavior of these metals could not be explained in this investigation.

The Group B analytes (As, $\mathrm{Co}, \mathrm{Fe}$, and $\mathrm{Mn}$ ) exhibit relatively consistent correlation between the two methods (paired $t$-test $>0.002$ ) and relatively minor deviation of regression slopes (between 1.05 and 0.89 ) from the ideal slope (Fig. 2). Testing the hypothesis showed that the regression slope for the Fe data was significantly different from slope $=1.0$, but As, Co, and $\mathrm{Mn}$ showed less significant differences. The analytes in this group are heavy metals commonly associated with iron and manganese minerals in the soils after weathering from sulfide or carbonate minerals in the parent rocks. These minerals are readily dissolved during the acid digestion, resulting in relatively good agreement between the two methods. The paired $t$-test result for $\mathrm{Fe}$ showed a much better (0.0021) correlation than did the result for the Group A analytes, but the ADS method considerably underestimated the mean Fe concentrations. Nevertheless, such good correlation was not expected, because $\mathrm{Fe}$ is also a minor structural component of illite and biotite minerals in the soils. The only possible explanations for the good correlation are that Fe was more readily leached by the acid dissolution than other structural elements or that the amounts of $\mathrm{Fe}$ in the silicate minerals were too small to influence the relationship. Iron oxide minerals formed during pedogenesis are the dominant $\mathrm{Fe}$ phase in ORR soils. 

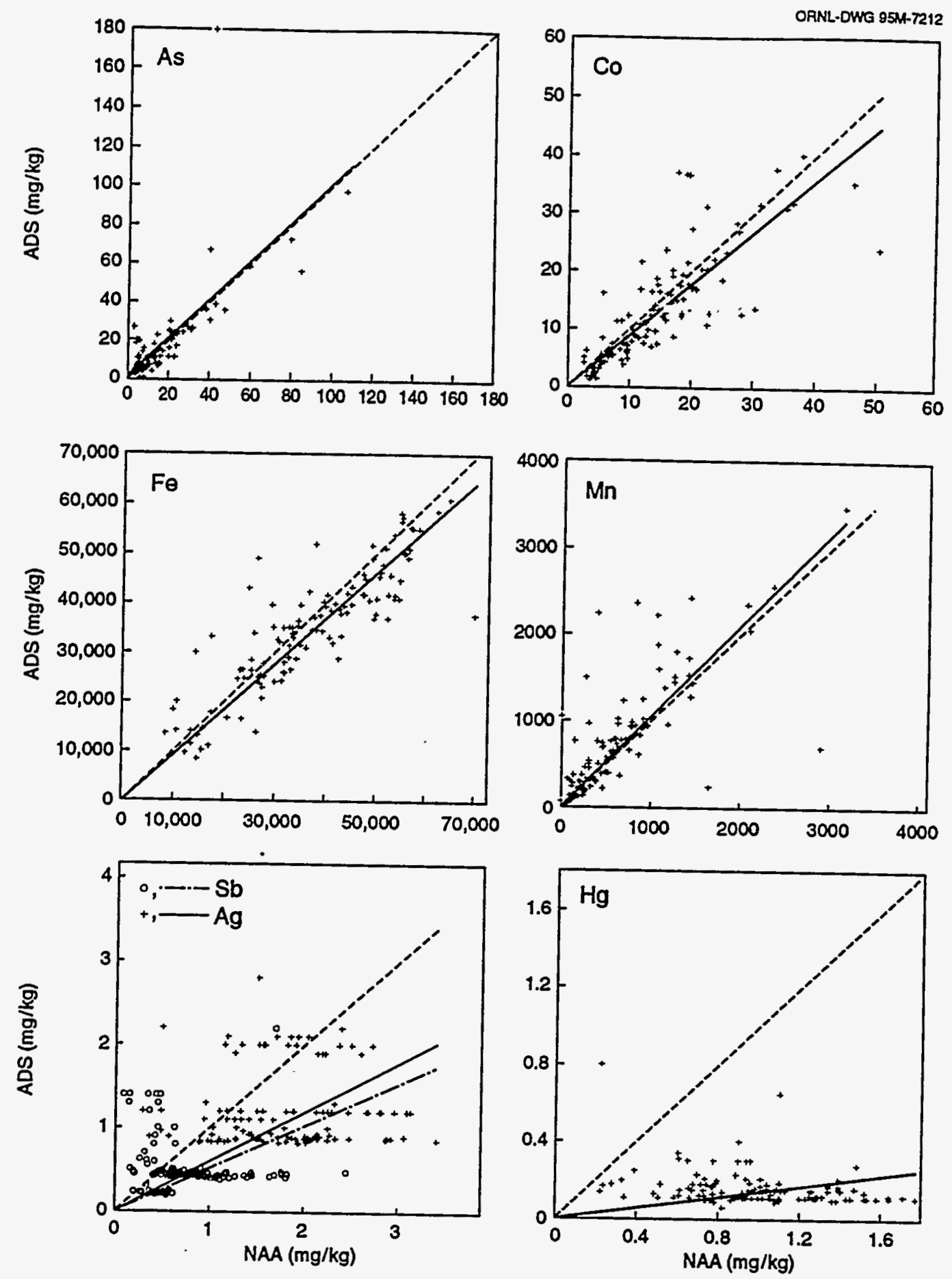

Fig.2. Scatter diagrams of $\mathrm{As}, \mathrm{Co}, \mathrm{Fe}, \mathrm{Mn}, \mathrm{Sb}, \mathrm{Hg}$, and $\mathrm{Ag}$ concentrations determined by the ADS and NAA methods. 
The Group $\mathrm{C}$ analytes $(\mathrm{Sb}, \mathrm{Hg}$, and $\mathrm{Ag}$ ) showed significant differences in the $t$-test (Table 1 ) and the regression slopes (Table 2). The poor correlation between the two methods in this case resulted from the lack of detect data in the ADS data set. Most of the ADS data were close to or below the detection limit used for each sample delivery group. The scatter diagrams of $\mathrm{Sb}, \mathrm{Hg}$, and $\mathrm{Ag}$ in Fig. 2 illustrate the multiple detection limits used for different sample delivery groups and the problem associated with undetects in the estimation of means. For a more meaningful interpretation of data that have few detects and many undetects, the ADS data should be treated with a different statistical approach ${ }^{1}$. The ADS method could provide more detects if the soil samples were leached with a high soil-to-solution ratio or the leachates were concentrated after extraction. The results demonstrated that the NAA method provided more reliable data than the ADS method did for the Group $C$ analytes.

Among the Group D analytes, ${ }^{232} \mathrm{Th}$ and ${ }^{238} \mathrm{U}$ showed reasonably good agreement on mean values between the two methods, although a noticeable scattering of data was observed along the $y$-axes (representing the ADS data) shown in Fig. 3. The paired $t$-tests showed excellent correlation for ${ }^{232} \mathrm{Th}$ and ${ }^{238} \mathrm{U}$ but very poor correlation for ${ }^{235} \mathrm{U}$ (Table 1). The arithmetic means also showed a large difference in the ${ }^{235} \mathrm{U}$ values between the two methods. Such noticeable differences between the results for the two uranium isotopes was not expected, because both isotopes were separated and counted at the same time. The quality of the uranium isotope data was examined by plotting activities of ${ }^{235} \mathrm{U}$ vs ${ }^{238} \mathrm{U}$ for the two different methods (Fig. 3). The two scatter plots indicated that the NAA data were scattered less (smaller activity range) than the ADS data. Furthermore, the uranium isotopic ratio for the NAA data was closer to the natural isotopic abundance ratio $\left({ }^{235} \mathrm{U} /{ }^{238} \mathrm{U}=0.0072\right)$, although the two uranium isotopes were determined independently. The ADS method, however, provided a much larger ratio (0.0134) than the natural isotopic abundance ratio, although they were determined from the same batch and through the same process until counting was performed on the isotopes. Another uranium isotope, ${ }^{234} \mathrm{U}$, was also analyzed by the ADS method at the same timel. The results showed that the isotopic ratio of ${ }^{234} \mathrm{U}$ to ${ }^{238} \mathrm{U}$ in the soils was close to the natural activity ratio $(0.99)$. The apparent overestimation of the ${ }^{235} \mathrm{U}$ activity could be caused by separation or counting problems associated with alpha spectrometry (an ADS method). The ${ }^{232}$ Th result showed excellent regression between the two methods (Table 2), but the NAA method had a smaller concentration range, as seen from the ${ }^{238} \mathrm{U}$ scatter diagram (Fig. 3). The ${ }^{232} \mathrm{Th}$ and ${ }^{238} \mathrm{U}$ data alone did not indicate which is the preferred method, but the ${ }^{235} \mathrm{U}$ data strongly suggested that the NAA method is better than the ADS method.

In conclusion, the ADS method underestimated most of the analytes examined, except in the case of a few radionuclides and heavy metals, and that is certainly consistent with the hypothesis established in this data evaluation. Trend and statistical analyses of the data suggest that the incomplete dissolution of silicate minerals during acid digestion is the major contributor to the observed differences. Other digestion methods ${ }^{14,15}$ will provide complete dissolution of the minerals, but these methods are not used by environmental remediation projects for many different reasons. Most environmental remediation projects are interested in heavy metals and in a simple procedure. Therefore, the ADS method could provide satisfactory information to the customers. A potential problem, even when a heavy metal is the concern, is the uncertainty related to the dissolution. If the contaminant is in particulate forms, a portion of the metal could remain with residue after the standard leaching process of the ADS method.

For background-level determination, the NAA method was much better than the ADS method in terms of accuracy, sensitivity, and cost. The disadvantage of NAA is its inability to quantify several metals $(\mathrm{Be}, \mathrm{Cd}, \mathrm{Se}$, and $\mathrm{Pb})$ and radionuclides $\left({ }^{90} \mathrm{Sr},{ }^{99} \mathrm{Tc}\right.$, and $\left.{ }^{239} \mathrm{Pu}\right)$ related to current 

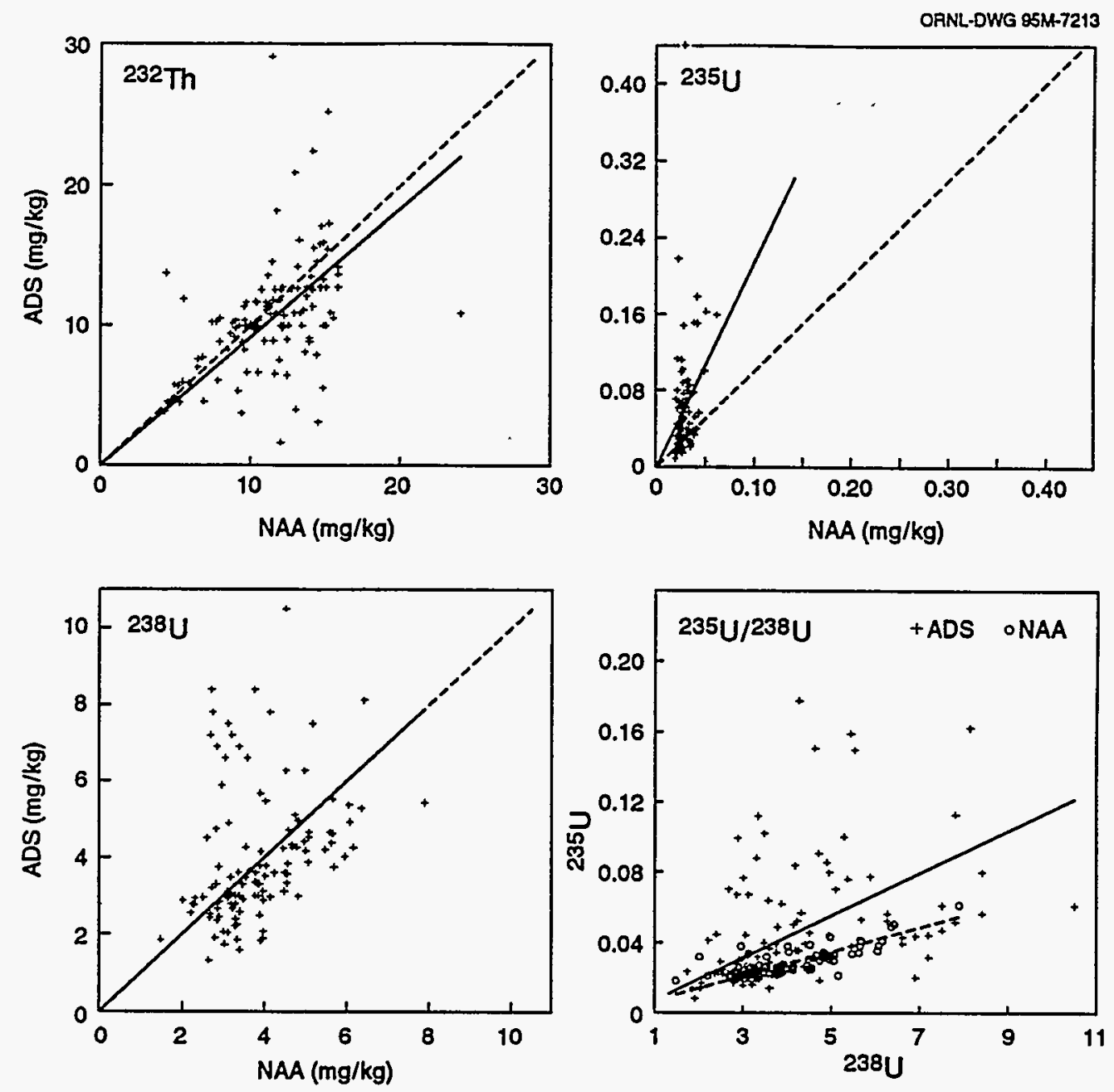

Fig. 3. Scatter diagrams of ${ }^{232} \mathrm{Th},{ }^{235} \mathrm{U}$, and ${ }^{238} \mathrm{U}$ concentrations determined by the ADS and NAA methods and a ratio diagram of $235 \mathrm{U}$ to ${ }^{238} \mathrm{U}$ concentrations determined by the ADS and NAA methods. 
environmental problems in the United States. The NAA method is available in most countries, and its application should be expanded for environmental research and remediation.

This data evaluation is intended to provide environmental remediation projects with site-specific, quality data for background concentrations of potential contaminants in soils. The analytes' concentrations in the ORR background soils were compared to reference soil data (arithmetic means and observed ranges) from the eastern United States, which are shown in Table $1^{16,17}$. The analytes in the ORR soils have lower arithmetic means and narrower observed concentration ranges $^{1}$ (not shown in Table 1) than the analytes in the eastern U.S. soils as a whole. The large observed concentration ranges in the referenced study were expected, because the study collected samples from a wide area (east of the 96th meridian of the U.S. continent) that has many different soils developed under different environmental conditions and from different parent materials. Such large variability is one of the many reasons that regional reference values are not applicable for site-specific environmental assessment. Environmental remediation decisions are often made on the basis of risk assessment. The usage of higher background values means lower risk at the contaminated sites, because a portion of contaminated areas could be classified as relatively clean if one uses the upper range values.

\section{Acknowledgment}

The authors wish to thank T. L. Hatmaker, C. W. McGinn, and D. M. Carden, D.C. Glasgow, F. F. Dyer, L. Robinson and other team members for their contributions to the Oak Ridge Background Soil Characterization Project. This research was supported by Environmental Restoration Program and Office of Technology Development of U.S. Department of Energy and conducted at Environmental Sciences Division of Oak Ridge National Laboratory, which is managed by Lockheed Martin Energy Systems, Inc., under contract DE-AC05-84OR21400 with the U.S. Department of Energy.

\section{References}

1. U.S. Department of Energy, Final Report on the Background Soil Characterization Project at the Oak Ridge Reservation, Oak Ridge, Tennessee, DOE/OR/01-1175/V1,2,3, ES/ER/TM-84, Lockheed Martin Energy Systems Inc., Oak Ridge, Tenn., USA (1995).

2. U.S. Environmental Protection Agency, Contract Laboratory Program Statement of Work for Inorganics, U.S. Environmental Protection Agency, Las Vegas, Nev., USA (1990).

3. Oak Ridge Environmental Information System (OREIS v.2.0.7), ORACLE database, Lockheed Martin Energy Systems, Inc., Oak Ridge, Tenn., USA (1995).

4. D. R. Watkins, S. Y. Lee, T. L. Hatmaker, C. W. McGinn, B. D. Nourse and R. L. Schmoyer, B. B. Burgoa, D. A. Lietzke, Proceedings of the Symposium on Waste Management, Tucson, Ariz., USA Vol. 2 (1994), 957-962.

5. D. C. Glasgow, F. E. Dyer, L. Robinson, J. Radional. and Nucl. Chem., 192 (1995) 361.

6. L. Robinson, F. E. Dyer, D. W. Combs, J. W. Wade, N.A. Teasley, J. E. Carlton, A. L. Ondracek, J. R. Stokely, J. Radional. and Nucl. Chem., 179 (1994) 305.

7. U.S. Environmental Protection Agency, Test Methods for Evaluating Solid Waste Vol. 1A: Laboratory Manual, Physical/Chemical Methods, SW-846: Method 3050, U.S. Environmental Protection Agency, Cincinnati, Ohio, USA (1986).

8. U.S. Environmental Protection Agency, Test Methods for Evaluating Solid Waste Vol. 1A: Laboratory Manual, Physical/Chemical Methods, SW-846: Method 7470, U.S. Environmental Protection Agency, Cincinnati, Ohio, USA (1986).

9. U.S. Environmental Protection Agency, Cincinnati, Ohio, USA, Radiochemistry Procedures Manual, EPA 520/584-006 U.S. Environmental Protection Agency, Las Vegas, Nev., USA (1984). 
10. SAS Institute, Inc., The MEANS Procedure, SAS Procedures Guide, Ver. 6, 4th ed., SAS Institute, Inc., Cary, N. C., USA (1990).

11. SAS Institute, Inc., The REG Procedure, SAS/STAT User's Guide, Ver. 6, 4th ed., SAS Institute, Inc., Cary, N. C., USA (1989).

12. D. N. Shirley, J. Petrol., 28 (1987) 835.

13. S. Y. Lee, D. H. Phillips, J. T. Ammons, D. A. Lietzke, Proceedings of the VIIIth International Working Meeting of Soil Micromorphology, L. A. Douglas (ed.), Elsevier, New York, N.Y., USA (1990), 511-517.

14. M. L. Jackson, Soil Chemical Analysis, Prentice-Hall, Inc., Englewood Cliffs, N. J., USA (1954).

15. M. L. Jackson, Soil Chemical Analysis-Advanced Course, 2nd ed. Department of Soils, University of Wisconsin, Madison, Wisc., (1975).

16. H. T. Shacklette, J. G. Boerngen, Elemental Concentrations in Soils and Other Surficial Materials of the Conterminous United States, U.S. Geological Survey Professional Paper 1270, U.S. Government Printing Office, Washington, D.C., USA (1984).

17. W. L. Lindsay, Chemical Equilibria in Soils, John Wiley \& Sons, New York, N.Y., USA (1979), 7-8. 